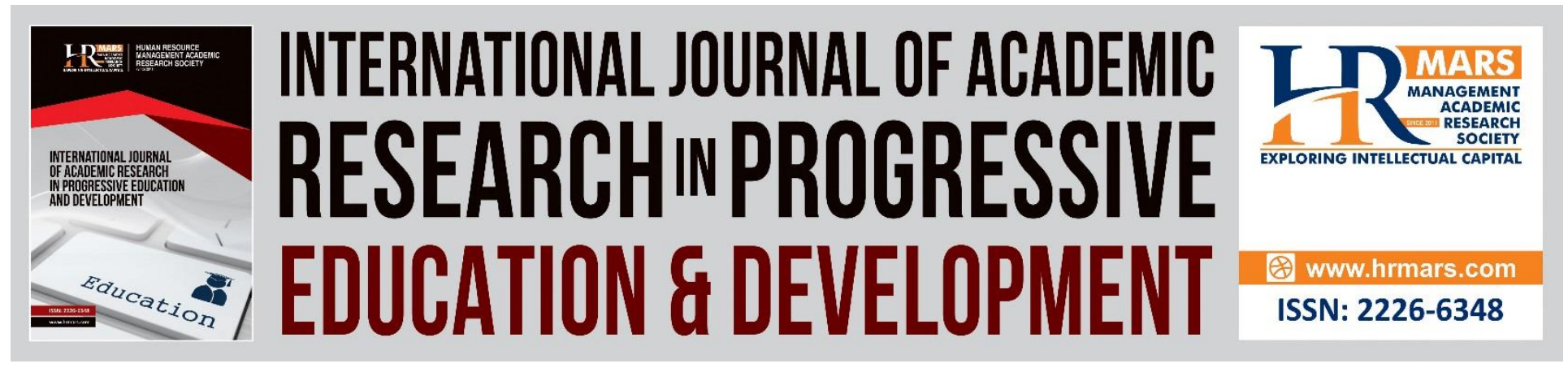

\title{
Crowdsourcing and Library Performance in Digital Age
}

Nur Aizatul Zakaria and Che Zainab Hj. Abdullah

To Link this Article: http://dx.doi.org/10.6007/IJARPED/v7-i3/4353

DOI: $10.6007 /$ IJARPED/v7-i3/4353

Received: 08 June 2018, Revised: 23 June 2018, Accepted: 18 July 2018

Published Online: 20 July 2018

In-Text Citation: (Zakaria \& Abdullah, 2018)

To Cite this Article: Zakaria, N. A., \& Abdullah, C. Z. H. (2018). Crowdsourcing and Library Performance in Digital Age. International Journal of Academic Research in Progressive Education and Development, 7(3), $127-136$.

Copyright: (C) 2018 The Author(s)

Published by Human Resource Management Academic Research Society (www.hrmars.com)

This article is published under the Creative Commons Attribution (CC BY 4.0) license. Anyone may reproduce, distribute, translate and create derivative works of this article (for both commercial and non-commercial purposes), subject to full attribution to the original publication and authors. The full terms of this license may be seen at: http://creativecommons.org/licences/by/4.0/legalcode

Vol. 7, No. 3, July 2018, Pg. 127 - 136

http://hrmars.com/index.php/pages/detail/IJARPED

JOURNAL HOMEPAGE

Full Terms \& Conditions of access and use can be found at http://hrmars.com/index.php/pages/detail/publication-ethics 


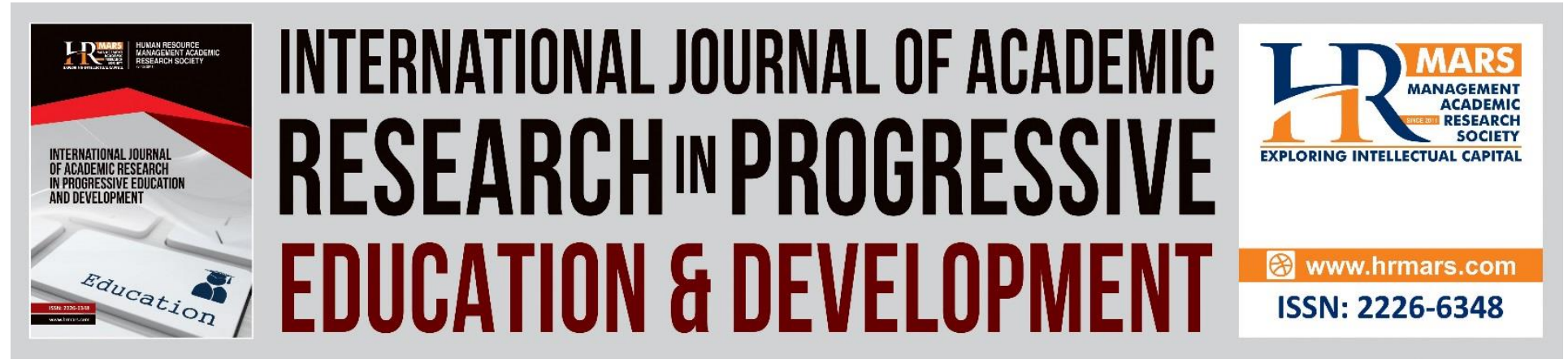

\title{
Crowdsourcing and Library Performance in Digital Age
}

\author{
Nur Aizatul Zakaria and Che Zainab Hj. Abdullah \\ Faculty of Information Management, Universiti Teknologi MARA (UiTM) \\ UiTM Selangor, Malaysia \\ Email: nuraizatul24@gmail.com, cheza347@salam.uitm.edu.my
}

\begin{abstract}
Digital libraries have been substituting the printed resources into electronic resources with the advent of technology in order to share the information online with the user community and also make the information accessible 24/7. Crowdsourcing is a process of gathering the information and knowledge among crowd of people, via the Web and it can be paid or unpaid. Crowdsourcing is one of endeavour to gain contributions from online community in obtaining views, ideas and contents is crowdsourcing. The purpose of this paper is to identify type of crowdsourcing that can be implementing in order to improve library performance in digital age. In this conceptual paper, an attempt has been made to discuss the concept of crowdsourcing, typology of crowdsourcing and also how those can be related with library performance in digital age. This study would be beneficial to the libraries as well as researchers as this study would provide the necessary information on the crowdsourcing and its contribution towards library performance. Keywords: Crowdsourcing, Library Performance, Digital Age, Library Management

\section{Introduction}

With the advancement of technology along with the development of Web 2.0 concepts, the Web users have widely promoting the idea of openness, knowledge sharing and also global cooperation. The term of crowdsourcing was introduced by Jeff Howe in 2006 as 'the act of taking job traditionally performed by a designated agent and outsourcing it to an undefined, mostly large group of people in community in the form of an open call'. Crowdsourcing itself is the combination of two words, crowd, which means a large group of people or community, and also outsourcing, which means obtains goods or services by contract form outsider.
\end{abstract}

As been stated by Brabham (2008), crowdsourcing can be identified as one of the appropriate model to utilize collection of talents, ideas by aggregating collective intelligence and knowledge among crowd of people. He also listed several need of crowdsourcing in his article including, overcome staff shortage, accomplish libraries' goals within limited time, build good relationship 
Vol. 7, No. 3, July 2018, E-ISSN: 2226-6348 @ 2018 HRMARS

among libraries and users, enhance the quality of library services that by fulfilling users' needs, add value to the library resources by fixing and commenting the materials and last but not least develop trust and loyalty among the library users.

Issues

Instead of its advantages or need, the implementation of crowdsourcing also needs to consider its disadvantages since several articles had identified those detractions. According to Floren (2012), several detractions such as questionable ownership, lack of member productivity also risk of having bad reputation been identified to occur during crowdsourcing process. For example, crowd members will lend their talents and ideas in open source where most of people will communicate and interact with each other in one space. Among crowd members, there can be a competitor that tried to steal the ideas and claim as his. So, it will be questioned whose rights it is. However, each thing has own advantages and disadvantages. Badariah et. Al (2013) had proved crowdsourcing can be well adopted and utilized when a large group of individuals working within their own interest and those people help and allow the organization cope with difficult and time consuming to be tackled in limited time.

The growth of Internet introducing electronic document exchange services, e-payment platforms and deployed solutions based on telework. Therefore, libraries also took this advantage of using the intellectual potential of online communities in gaining knowledge and information to improve their performance. Crowdsourcing has emerged as an endeavour in order to overcome the challenges of libraries in digital age such as inviting library community to mark the errors in cataloguing and creating e-books. According to Oomen \& Aroyo (2011), "crowdsourcing has been seen a way to create a more open, connected and smart cultural heritage".

There is some limitation for library to implement crowdsourcing to store and access information. Therefore, there is a need for the libraries to implement crowdsourcing in order to gather the information, transform digital collections into Internet collaborative sharing and also preserve information in this digital age. This article explores at type of crowdsourcing that can be implemented at the present time in libraries. Each type of crowdsourcing will be followed by elaboration found in previous literature.

\section{Literature Review}

Crowdsourcing can improve the library performance in digital age. This paper intended to create a conceptual framework that relate to library performance with the types of crowdsourcing that include social-production crowd, crowd wisdom, crowd creation, crowd voting and crowd funding.

\section{Microtasks}

In this global era, one of technology tool which is micro-task crowdsourcing is rapidly gaining popularity among communities, business as well as non-profit organization such as archives, museums and libraries in performing their daily operations. Like another services, micro-task 
INTERNATIONAL JOURNAL OF ACADEMIC RESEARCH IN PROGRESSIVE EDUCATION AND DEVELOPMENT

Vol. 7, No. 3, July 2018, E-ISSN: 2226-6348 @ 2018 HRMARS

crowdsourcing can be a platform that affecting organization's performance, speed and also quality.

According to Difallah et.al. (2015), in order to cope with information overload, manual data processing is necessary to create value or support decision making. So, outsourcing data processing such as micro-task crowdsourcing is a need in performing the simple tasks, for example, image tagging, audio transcription and translation. In a simple word, micro-tasks can be defined as paid microtask crowdsourcing whereas community or workers receive monetary compensation or other benefits for successfully completing a microtask. The main purpose in implementing micro-tasks crowdsourcing in the library is to delegate librarian tasks so that they can focus more on technical and critical part rather than simple tasks or activities.

Gadlraju et.al. (2015) had stated in their article regarding overview of frequently crowdsourced microtasks. Microtasks crowdsourcing can be categorized into several examples of job that can be performed. Information finding is a task that will be delegate among community in searching the information or data of something. For example, the library needs the specific information regarding to the policy of British University Library. The librarian may ask the crowd in order to save time. Interpretation and analysis. These tasks rely on the crowd to use their interpretation skills during task completion. Content creation. This task usually required crowd to generate new content for a document including provide product descriptions.

Micro-tasks crowdsourcing can be a performance monitor and can be done by automatically detecting malicious workers and effectively routing tasks to the right workers in the crowd. Gadlraju et.al. (2015) stated that micro-tasks platform can detect poor performance workers. For example, advanced results aggregation techniques can effectively detect low-quality workers in the crowd.

\section{Macrotasks}

Macrotasks is one type of crowdsourcing and it is different from microtasks crowdsourcing. Macrotasks need worker to done independently, they required a fixed amount of time and also require crowd to have specific and special skills. The organization may hire the worker form crowd for single tasks and the worker need to get specific skill for a job or project. The organization and the worker will communicate over the Internet and been paid by the task had been done. For example, library may assign worker from crowd that has cataloguing skill in completing the tasks regarding to cataloguing. The examples of job can be done in macrotask crowdsourcing regarding to general business work, web design, writing and editing assistance and also application development.

In some cases, macrotasking is similar to freelancing. Macrotasks crowdsourcing is one of the platform that enable workers to find the people that able to do the job through open, public market. According to Grier (2013), through macrotasks crowdsourcing the workers able to hire the person with the exactly skills you need and at the same, the workers get what they 
Vol. 7, No. 3, July 2018, E-ISSN: 2226-6348 @ 2018 HRMARS

have paid for. In library environment, librarians just outsourced the work to the outsider that have library skills and paid the people accordingly.

Together with the demand for complex tasks and their supporting workflows, customers are increasingly interested in performance guarantee, for example the optimization of expert crowdsourcing in terms of cost, quality and timeliness. According to Schmitz and Lykourentzou (2016), workers require the tasks to be done upon a certain deadline. Therefore, there are some barriers related to time consuming. The workers that been hired from crowd, which the people are available at the specific time slots or maybe the tasks is not within their skills or fields. Optimizing for time is quite crucial, so that the macro-task crowdsourcing can be done efficiently, so that any organization that implements macrotasks crowdsourcing be able to improve their performance in delivering services and producing goods on time.

Macrotasks crowdsourcing able to help the workers to improve their job performance which are; creating more flexible structure that can quickly respond to changing conditions, improve job performance as well as organization performance, get a higher-quality and the most important, reducing the costs.

\section{Self-Organised Crowd}

Nowadays, in order to encourage community in developing creativity, self-organised crowd had been introduced. Previous research had stated some of the innovative applications are using self-organised crowd as a platform. Self-organised crowd also known as crowd creation. This concept had been introduced by Jeff Howe in 2006. According to Howe (2006), crowd creation is created in order to leverage abilities and insights from people in creating new products. Self-organised crowd is quite similar to crowd contests, which is the organiser post a challenge on the Web, something that organiser want to achieve and then offer a reward for the people who able to accomplish that challenge.

Self-organised crowd enable the crowd decide the best way to work and accomplish the challenge unlike microtask and macrotasks which worker assign the jobs or tasks to the crowd of people. The crowd should be able to creatively thinking how the task can be done and how to organize it.

David Alan Grier (2013) presented the a few examples in performing the self-organised crowd. First, the workers post a challenge in developing the new product on the Web in order to make the crowd to work on challenge. Crowd need to organize a team by themselves. The teams will compete among themselves to provide the best answer for the challenge. The best team winning and been compensated.

Even though there is no research regarding on implementation of self-organised crowd in library, it can be the best method in innovating the new library services base on peoples' insights and ideas. Since the library is creating self-organised crowd, they need to encourage the people to participate in order to develop creative and innovative thinking. Despite that, 
Vol. 7, No. 3, July 2018, E-ISSN: 2226-6348 @ 2018 HRMARS

self-organised crowd also can be powerful in gathering information in making a decision. The library can put a question regarding to their services to the crowd members and ask them to select the option. This will help the library to make a decision with the largest support.

\section{Crowd Wisdom}

In some circumstances, group of people can be remarkably intelligent and smarter rather than smarter person in them. Even though most of people in the group are not well informed, they can still reach a wise decision. This situation can be referred to crowd wisdom. According to Howe (2006), the concept of crowd wisdom is using the collective intelligence of people within or outside an organization to solve the problem and also to make decisions.

Surowiecki (2004) stated in his article regarding to the advantages of crowd wisdom when be applied in organization. According to him, the simplest example we can see is, a very popular search engine, Google, which work on the basis of wisdom of crowd. By calculating how many people visit certain pages, Google able to decide which page are more useful and influence towards the users. So, Google able to detect which pages are relevant to a particular search and listed down the search results according to votes.

Crowd wisdom is able to help any organization in achieving a decision through people of crowd. For instance, a library need to come with a decision whether they need service improvement or not. Through crowd wisdom, library able to hear the opinions and ideas of people and take into account what they have been said. There are no guarantees for the success. But, the organization will come up with the future scenarios or possible strategies that use the method of aggregating collective wisdom.

There are four elements required to form a wise crowd by Surowiecki (2004). The first one is diversity of opinion. Each person should have their own range of experiences, level of educations and opinions. They might be sharing their ideas to form good and wise decisions among the group. Second is independence. Surowiecki said people will think independently and prediction by one person is not influenced by others. The third one is decentralization. People in crowd may have their specific specialization and local knowledge. Last but not least, aggregation. Crowd wisdom can be a platform for turning private judgements into collective decisions. The author assumes that each person is not cornered with opinion of others and no term of copying each other in crowd wisdom.

\section{Crowdfunding}

Unlike the other form of crowdsourcing, crowdfunding is not about delegating the work. Crowdfunding is about raising the money in small donation from crowd of people. Crowdfunding is a relatively new phenomenon, also known as online, open, public and purposeful fundraising for specific projects and for a specific capital goal (Ghose, 2016). Libraries also take part in crowdfunding in order to sustain themselves in both short and long term. 
Vol. 7, No. 3, July 2018, E-ISSN: 2226-6348 @ 2018 HRMARS

According to Antonenko et al (2014), online crowdsourcing is a direct societal response to the financial crisis and to the consequences of tighter business loan regulations and diminished funding from any sources. This idea of crowdfunding was by Perry Chen, when he faced financial problems that become the barriers in culturally creative processes. In 2009, Kickstarter came with the idea in gaining early trust and acceptance crowdfunding initiatives within the library. Kendall (2014) said, the ideas of Kickstarter become a success and more people were encouraged.

When undertaking crowdfunding initiatives, it is compulsory to communicate with the public about projects' importance and the outcomes intended. Kim (2014) had said, authenticity, sincerity, and showing distinct ability to achieve the goal is necessary to convince the community bring more success towards library crowdfunding. Internal social capital is of utmost importance during the early active phase of a crowdfunding campaign. Providers of internal social capital are generally friends, family, co-workers, social media connections and other close organizations, including those organizations that have used the same crowdfunding platform. Crowdfunding projects that have good backing through donations or pledges early in the campaign are highly likely to succeed.

Crowdfunding initiatives are complicated projects with numerous possible whether it can be a success or failure. Good planning, outreach and marketing are clearly necessary for success, but good project choice is also one of the key known factors that will lead to a successful campaign. A good project decision will carefully consider how well the project fits within the organizational mission, the resources available to manage the initiative, the timing of the project, probable donor interest and a reasonable fundraising goal. This is because the community will convinced to fund with the solid and strong evidence of project. According to Economist.com (2013), the statistic showed the most crowdfunding projects is based on games, technology, film and video. The situation can be considered win-win situation when the organization reach financial goal and the crowdfunder find success as a community accomplishment.

\section{Library performance in Digital Age}

The previous research on library indicates that libraries physically stored all the materials and resources. The development of technology also gives the big impact towards library which turn traditional library towards digital library. It also provides a crucial effect toward library performance within this digital age.

Nowadays, as we are in the digital age, most of role of information in this age is in the form of digital. One of that is sharing information using the digital network. Information can be created, stored, organized, accessed and shared in various formats such as text, audio, video and other various forms by using the technology. With the advancement of technology, we can say library performance also rapidly improve from time to time.

The library performance can be evaluated by identifying the effectiveness of library delivering their services as well as librarian performance in handling their works or tasks. One of 
INTERNATIONAL JOURNAL OF ACADEMIC RESEARCH IN PROGRESSIVE EDUCATION AND DEVELOPMENT

Vol. 7, No. 3, July 2018, E-ISSN: 2226-6348 @ 2018 HRMARS

technology advancement that can be implementing in library is crowdsourcing. There are several types of crowdsourcing that have different roles in improving library performance, that can benefit various party, which are users, librarians and most important one, library.

\section{Conceptual Framework}

Figure 1 is a proposed theoretical framework that will be used to guide this research. The framework illustrates dependent variable (library performance); and the independent variable (cost-effective, free marketing, outsourcing potential, add value to data and data discoverable). The framework can be used in order to answer research question on how crowdsourcing influences library performance.

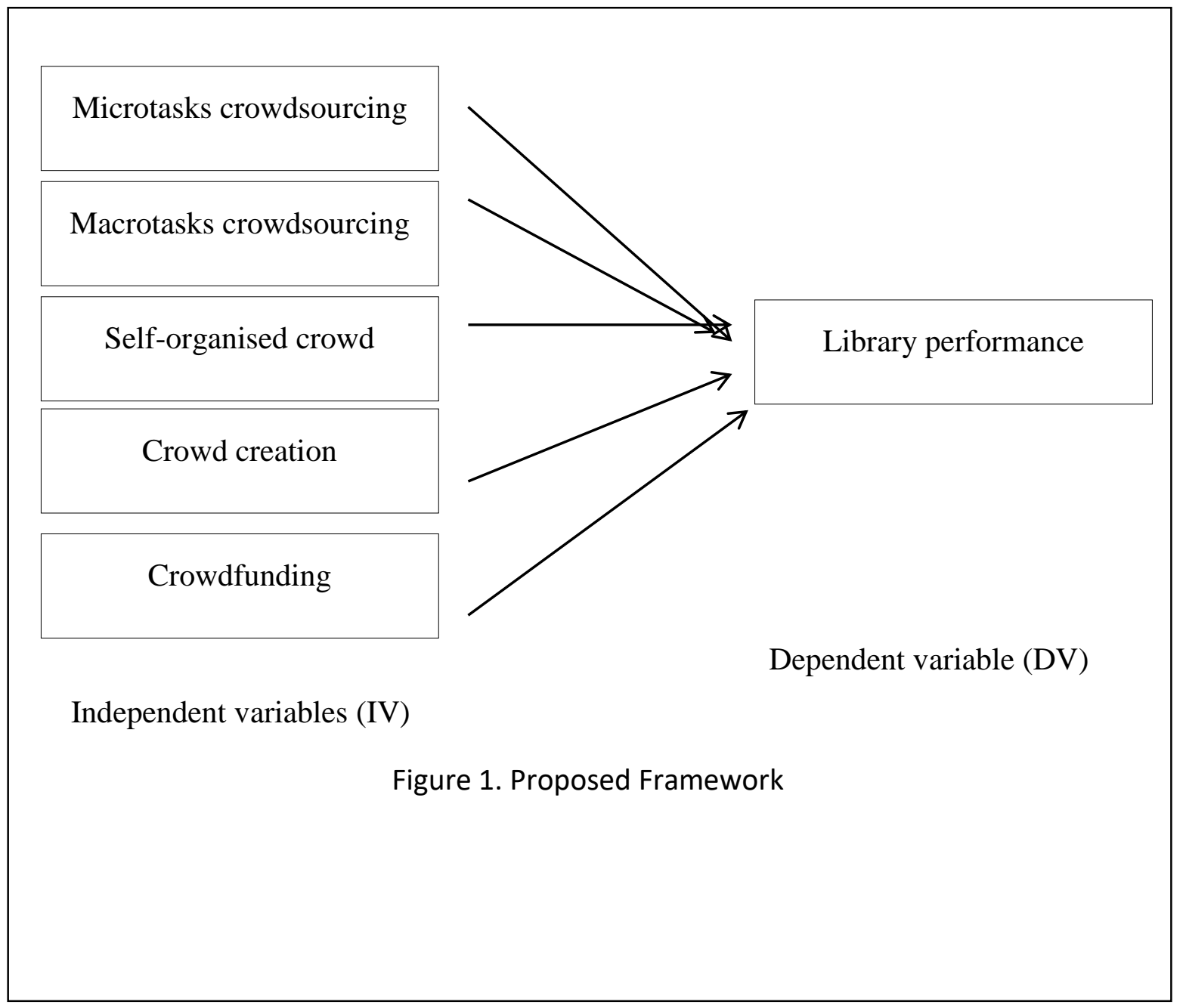

\section{Conclusion}

In summary, we can conclude that crowdsourcing can be a useful method for libraries organization to start generating ideas by people. By utilizing "power of masses", libraries able to identify what users' needs are looking into libraries. Throughout the previous researches, crowdsourcing is stated that bring several benefits towards library also improve library 
Vol. 7, No. 3, July 2018, E-ISSN: 2226-6348 @ 2018 HRMARS

performance in delivering services. Crowdsourcing involves collective interaction, intellectual contribution and also online sharing of digital collections with the users apart from the sharing assorted and scattered employees in library field. Regarding to those, the crowdsourcing should be encouraged by the libraries as it facilitates information gathering through which the information collection can be transformed.

Other than that, crowdsourcing also can be a flexible tool that can be used in the development of new products and services, and also tool using in marketing. Several libraries have proven the implementation of crowdsourcing can bring them tangible benefits that able the libraries to achieve most of their objectives. There are several benefits of crowdsourcing in achieving the goals such as achieve goals of library in a much a time faster, building new virtual space between libraries and communities, utilizing the knowledge, expertise and among people and also making data widely discoverable in many ways.

In the end, it can be said Library 2.0 can be developed by harnessing the power of crowdsourcing. Crowdsourcing enable the libraries to move forward in this digital age. So, the implementation of library should be encouraged to all the libraries in order to transform the library into Library 2.0 in this digital age. Therefore, future research should be done in order to collect more information regarding crowdsourcing towards library, for example, the benefits and contributions of crowdsourcing in libraries, the process of crowdsourcing within library and so on.

\section{References}

Chhatwal, A. \& Mahajan, P. (2015) "Crowdsourcing in libraries: an operational framework", International Journal of Digital Library Services, Vol 5 Issue:3

Gadlraju, U., Demartini, G., Kawase, R., \& Dietze, S. (2015) “Human beyond the machine: challenges and opportunities of microtask crowdsourcing" pp.5

Haas, D., Ansel, J., Gu, L., \& Marcus, A. (2015) “Argonaut: macrotasking crowdsourcing for complex data processing", Proceedings of the VLDB Endowment, Vol: 8 No. 12

Maubossin, M. J. (2007) "Explaining the wisdom of crowds: applying the logic diversity", Legg Mason Capital Management

Hossain, M., \& Kauranen, I. (2015) "Crowdsourcing: a comprehensive literature review",Strategic Outsourcing: An International Journal, Vol. 8 Issue: 1, pp.2-22, https://doi.org/10.1108/SO-12-2014-0029

Riley-Huff, D. A., Herrera, K., Ivey, S., \& Harry, T. (2016) "Crowdfunding in libraries, archives and museums", The Bottom Line, Vol. 29 Issue: 2, pp.67-85, https://doi.org/10.1108/ BL-03-2016-0014 
INTERNATIONAL JOURNAL OF ACADEMIC RESEARCH IN PROGRESSIVE EDUCATION AND DEVELOPMENT

Vol. 7, No. 3, July 2018, E-ISSN: 2226-6348 @ 2018 HRMARS

Schmitz, H., \& Lykourentzou, I. (2016) "It's about time: online macrotask sequencing in expert crowdsourcing" pp. 1-24.

Zhao, C. Y. \& Zhu, Q. (2016) "Conceptualizing task affordance in online crowdsourcing context", Online Information Review, Vol. 40 Issue: 7, pp.938-958, https://doi.org/10.1108/ OIR-06-2015-0192 